\title{
PERENCANAAN KEBUTUHAN KAPASITAS PRODUKSI PADA SP ALUMINIUM
}

\author{
Wawan K Risal, Puryani, dan Eko Nursubiyantoro \\ Jurusan Teknik Industri Fakultas Teknik Industri \\ Universitas Pembangunan Nasional "Veteran" Yogyakarta \\ Jl. Babarsari 2 Tambakbayan, Yogyakarta, 55281 \\ Telp. (0274) 485363 Fax: (0274) 486256
}

\begin{abstract}
ABSTRAK
PT SP Aluminium merupakan perusahaan manufaktur yang khusus memproduksi perlengkapan dapur, seperti wajan, panci, dan sebagainya. Strategi pemenuhan permintaan dilakukan dengan strategi produksi make to stock. Bahan baku utama yang digunakan untuk memproduksi produk-produk tersebut adalah aluminium. Pemasaran produk SP aluminum dilakukan melalui berbagai distributor di berbagai daerah dengan menyuplai wajan yang dipesan oleh para distributor sesuai dengan estimasi distributor terhadap permintaan wajan pada daerah masing-masing.

Tujuan penelitian agar perusahaan dapat melakukan perencanaan kebutuhan kapasitas produksi sesuai dengan kapasitas produksi yang tersedia pada lantai produksi sehingga mampu mendistribusikan wajan kepada distributor dalam jumlah yang tepat. Kekurangan kapasitas produksi yang terjadi dapat diambil kebijakan terbaik untuk mengatasi kekurangan kapasitas.

Hasil penelitian terjadi kekurangan kapasitas pada stasiun kerja Pencetakan Wajan Super ukuran 15 dan 16, Gerinda, Bubut, dan Polish. Kekurangan kapasitas yang terjadi diselesaikan terlebih dahulu dengan melakukan overtime selama tiga jam. Kemudian, kekurangan kapasitas yang masih terjadi pada stasiun kerja Bubut di periode delapan dan tiga puluh satu sebesar 68,43 menit dan 943,44 menit diselesaikan dengan cara mengsubkontrakkannya ke mitra perusahaan.
\end{abstract}

\section{Kata Kunci :Capacity Requirement Planning (CRP), overtime, subkontrak.}

\section{PENDAHULUAN}

PT SP Aluminium adalah perusahaan manufaktur yang memproduksi alat-alat rumah tangga seperti wajan, panci, ketel, dan citel, serta aksesoris-aksesori berbahan aluminium yang diproduksi berdasarkan pesanan. Proses produksi dari produk-produk PT SP Aluminium melewati 5 tahap, yaitu proses peleburan material, proses pencetakan, proses finishing 1, proses finishing 2, dan proses finishing 3. Proses-proses produksi ini dilakukan selama 6 hari dalam seminggu, yaitu pada hari senin sampai sabtu, dalam waktu 8 jam per hari yaitu dari pukul 08.0016.00 , sedangkan khusus untuk tahap peleburan, proses produksi dimulai dari pukul 03.00-08.00. Namun kapasitas yang tersedia bagi perusahaan tidak cukup untuk memenuhi permintaan dari pasar, hal ini ditunjukkan oleh data pengiriminan produk ke sejumlah distributor produk SP Aluminium, di mana pada data pengiriman barang kepada sembilan distributor SP Aluminium pada bulan Desember 2014, hanya pengiriman pada empat distributor saja yang tepat waktu dan kuantitas produk yang dikirim, begitu pula yang terjadi pada dua bulan sebelumnya. Berdasarkan pada hasil wawancara, hal tersebut terjadi karena lantai produksi tidak mampu memenuhi pesanan yang diberikan oleh bagian pemasaran. Jika hal ini terus terjadi, maka eksistensi perusahaan dapat terancam karena konsumen dapat beralih kepada kompetitor PT SP Aluminium.

\section{LANDASAN TEORI}

\section{Peramalan}

Peramalan adalah prediksi yang mengarahkan perusahaan untuk mengetahui berapa jumlah produk yang akan dijual di masa depan, dasar pengambilan keputusan penting, dan juga sebagai dasar perencanaan keputusan pembuatan jadwal produksi, inventori distribusi, pembelian, dan lain sebagainya sebagai fungsi dari permintaan pelanggan (Sheikh, 2002). Objek peramalan adalah data historis dari pemintaan suatu produk. Metode peramalan kuantitatif terbagi atas dua bagian, yaitu : 1) intrinsik, dan 2) ekstrinsik. Model ekstrinsik yang digunakan adalah model 
regresi kausal. Sedangkan model intrinsik terdiri atas beberapa model yaitu :

1. Moving averages model

2. Weighted moving averages model

3. Exponential smoothing

4. Trend line analysis model

5. Exponential smoothing with trend adjustment

Akurasi peramalan dilihat dari seberapa besar perbandingan antara nilai peramalan yang telah dilakukan dengan data permintaan aktual yang telah dikumpulkan.

\section{Perencanaan Agregat}

Perencanaan agregat adalah suatu bentuk perencanaan jangka menengah yang dilakukan dengan cara merencanakan permintaan item dalam satu kesatuan kelompok yang didefinisikan dalam bentuk satu unit pengukuran umum seperti jumlah unit output unit ataupun satuan waktu proses unit dalam industri manufaktur (Narasimhan et al, 1995). Perencanaan agregat akan menentukan tingkat kerja, lembur, dan tingkat per-sediaan dengan tujuan untuk meminimasi biaya. Untuk mencapai tujuan tersebut, tingkat tenaga kerja dalam proses produksi diterjemahkan sebagai biaya tenaga kerja, dan tingkat persediaan dapat digunakan untuk mengetahui kebutuhan ruang untuk melakukan penyimpanan (Narasimhan et al, 1995).

\section{Master Production Schedule (MPS)}

MPS merepresentasikan perencanaaan produksi perusahaan yang diekspresikan dalam konfigurasi, jumlah, dan tanggal spesifik. MPS terdiri dari (Sheikh, 2002) :

1. Produk jadi atau bagian sub-assembli utama (modul standar) yang dipro-duksi

2. Kuantitas dari masing-masing item yang diproduksi

3. Kapan item-iten tersebut siap untuk dikirim.

\section{Rough Cut Capacity Planning (RCCP)}

RCCP menyediakan data agregat informasi bagi manajamen puncak untuk mempertimbangkan perizinan kepada manajemen untuk melakukan perubahan kapasitas (merekrut lebih banyak karyawan/buruh, membeli lebih banyak peralatan) untuk mencapai target yang telah ditentukan melalui MPS (Sheikh, 2002). Objektif dari RCCP adalah untuk mengidentifikasi sumber daya yang dibutuhkan apakah telah sesuai dengan MPS (Tersine, 1994). Terdapat empat kebijakan yang umumnya diambil oleh manajemen untuk me-ningkatkan kapasitas produksi perusahaan agar dapat memenuhi target. Keempat kebijakan itu adalah (Fogarty et al, 1991) :

1. Lembur (overtime)

2. Melakukan subkontrak

3. Melakukan pergantian jalur

4. Menambah personel

\section{Material Requirement Planning (MRP)}

MRP adalah sistem perencanaan produksi dan pengendalian inventori terkomputerisasi yang bertanggung jawab untuk menjadwalkan produksi dari seluruh item yang berada di bawah level produk akhir, merekomendasikan work orders dan purchase orders, dan melakukan penjadwalan ulang jika diperlukan. Objektif manajerial dari MRP adalah untuk menyediakan material yang tepat pada waktu yang tepat dan tempat yang tepat sesuai jadwal agar melengkapi kebutuhan produk. Tujuan utama dari MRP adalah untuk merencanakan kebutuhan dari permintaan item dependent (Tersine, 1994).

\section{Capacity Requirement Planning (CRP)}

CRP memberikan penilaian secara terperinci dari sumber-sumber daya yang dibutuhkan untuk melaksanakan pesananpesanan manufaktu-ring yang diciptakan melalui proses MRP, CRP memvalidasi MRP agar perencanaan yang dilakukan sebelumnya telah sesuai dengan kapasitas tersedia (Gaspersz, 2012). Tujuan utama CRP adalah untuk menunjukkan perbandingan antara kemampuan yang dapat dibebankan pada work center dengan work orders yang diusulkan pada setiap periode waktu.

\section{METODOLOGI PENELITIAN \\ 1. Objek Penelitian}

Objek yang diteliti adalah lantai produksi wajan. Pemilihan objek tersebut berdasarkan pada hasil wawancara dengan kepala departemen produksi yang mengatakan bahwa keterlambatan sering terjadi pada objek 
tersebut padahal produk wajan merupakan produk unggulan perusahaan ini.

\section{Data Yang Digunakan}

- Data Sekunder

Data ini adalah data yang bersumber langsung dari orang pertama yang berkaitan dengan penelitian ini. Data-data yang diperoleh dengan cara tersebut sebagai berikut

a. Waktu proses produksi

b. Routing files process

- Data sekunder

Data ini diperoleh melalui pihak-pihak di luar objek penelitian ini namun masih relevan dengan masalah yang juga dialami oleh objek yang diamati. Data-data tersebut adalah :

a. Data permintaan wajan

b. Data jam kerja dan jumlah pekerja

c. Bill of material produk

\section{Pengolahan Data}

Pengolahan data yang dilakukan dalam penelitian ini dibagi menjadi tiga kelompok pengolahan, yaitu melakukan agregasi terhadap permintaan produk, pengolahan data peramalan permintaan, dan yang kedua adalah pengolahan data untuk sistem manufaktur MRP II. Berikut adalah langkah-langkah dari masing-masing pengolahan data :

1. Melakukan agregasi terhadap permintaan produk.

2. Pengolahan data peramalan permintaan. Langkah-langkah pengolahan data untuk peramalan adalah sebagai berikut : a. Identifikasi pola historis dari data aktual permintaan.

b. Memilih model peramalan yang sesuai dengan pola historis permintaan

c. Melakukan perhitungan dengan menggunakan model yang telah dipilih.

d. Melakukan analisis data berdasarkan perhitungan peramalan model peramalan yang dipilih.

e. Memilih model peramalan yang tepat berdasarkan hasil analisa data yang dilakukan.

3. Pengolahan data untuk merencanakan kebutuhan kapasitas

Langkah-langkah perencanaan kebutuhan kapasitas produksi adalah sebagai berikut :

a. Menentukan jadwal induk produksi dari hasil peramalan dengan mendisagregasikannya menggunakan MPS.

b. Melakukan perhitungan RCCP

c. Menyusun perencanaan kebutuhan material dari MPS menggunakan MRP.

d. Melakukan perhitungan terhadap kapasitas produksi dibutuhkan berdasarkan perencanaan MRP dengan menggunakan CRP.

\section{PENGOLAHAN DATA DAN}

ANALISIS HASIL

1. Pengumpulan Data

- Data permintaan produk wajan

Tabel 4.1 Data Permintaan Wajan

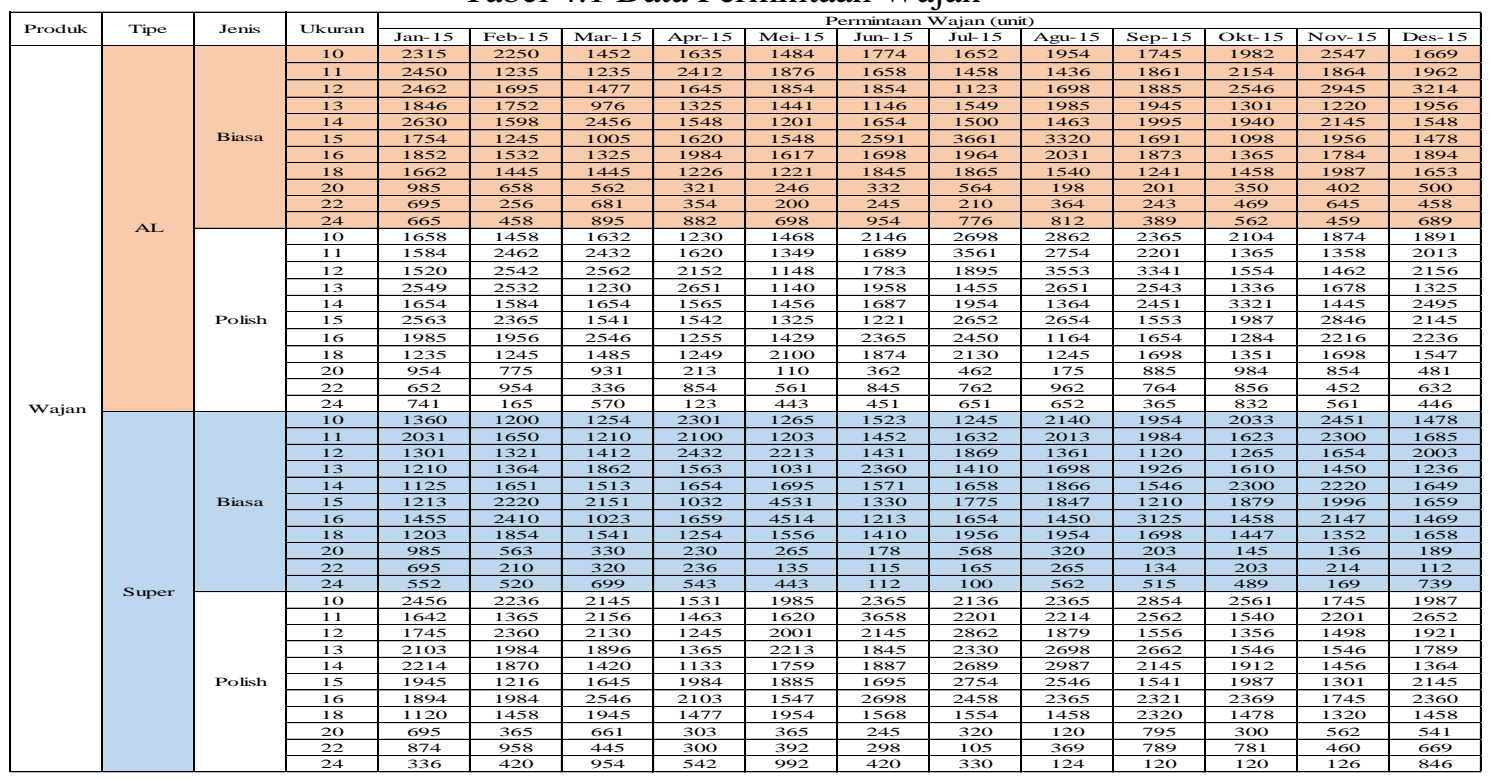


- Bill of material produk wajan

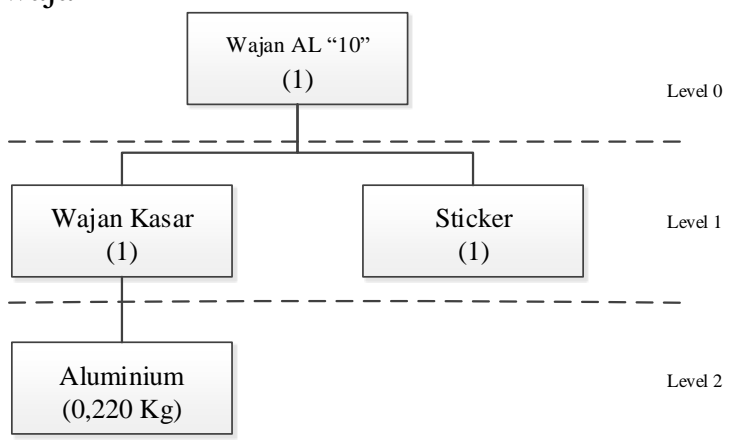

Gambar 4.1 Bill of material produk wajan

- Data kapasitas tersedia pada stasiun kerja

Tabel 4.2 Kapasitas tersedia stasiun kerja

\begin{tabular}{|c|c|c|c|c|c|}
\hline \multicolumn{2}{|c|}{ Stasiun } & Jam Kerja & Utilasasi & Efisiensi & $\begin{array}{c}\text { Kapasitas } \\
\text { (Menit) }\end{array}$ \\
\hline \multirow{11}{*}{ Cetak AL } & 10 & \multirow{22}{*}{$\begin{array}{l}03.00-05.00 \\
08.00-16.00\end{array}$} & \multirow{28}{*}{$100 \%$} & \multirow{22}{*}{$85 \%$} & \multirow{22}{*}{13260} \\
\hline & 11 & & & & \\
\hline & 12 & & & & \\
\hline & 13 & & & & \\
\hline & 14 & & & & \\
\hline & 15 & & & & \\
\hline & 16 & & & & \\
\hline & 18 & & & & \\
\hline & 20 & & & & \\
\hline & 22 & & & & \\
\hline & 24 & & & & \\
\hline \multirow{11}{*}{ Cetak Super } & 10 & & & & \\
\hline & 11 & & & & \\
\hline & 12 & & & & \\
\hline & 13 & & & & \\
\hline & 14 & & & & \\
\hline & 15 & & & & \\
\hline & 16 & & & & \\
\hline & 18 & & & & \\
\hline & 20 & & & & \\
\hline & 22 & & & & \\
\hline & 24 & & & & \\
\hline \multicolumn{2}{|c|}{ Kikir } & \multirow{6}{*}{$08.00-16.00$} & & $90 \%$ & 56160 \\
\hline \multirow{2}{*}{\multicolumn{2}{|c|}{$\begin{array}{c}\text { Gerinda } \\
\text { Bubut }\end{array}$}} & & & $95 \%$ & 118560 \\
\hline & & & & $90 \%$ & 112320 \\
\hline \multicolumn{2}{|c|}{ Polish } & & & $90 \%$ & 112320 \\
\hline \multicolumn{2}{|c|}{ Rakit } & & & $100 \%$ & 62400 \\
\hline \multicolumn{2}{|c|}{ Packing } & & & $100 \%$ & 99840 \\
\hline
\end{tabular}

\section{Pengolahan Data}

- $\quad$ Agregasi Permintaan Produk

Perhitungan agregasi dilakukan sebagai tahap dalam menentukan agregat permintaan seluruh produk berdasarkan pada satu ukuran yang sama, dalam penelitian ini permintaan produk diagregasi ke dalam ukuran massa aluminium yang digunakan untuk membuat satu unit produk. maka perhitungan dari agregat permintaan produk seperti yang dicontohkan pada permintaan wajan AL Biasa "10" bulan Januari sebagai berikut :
Agregat Permintaan Januari

$=$ Demand bulan Januari $\mathrm{x}$ massa aluminium

$=2315$ unit $\mathrm{x} 0.2200 \mathrm{Kg}$

$=509,300 \mathrm{Kg}$

- $\quad$ Peramalan Permintaan Produk

Peramalan dilakukan guna memperkirakan jumlah permintaan yang terjadi pada periode mendatang, sehingga perusahaan mampu untuk merencanakan sejak dini kebutuhan kapasitas perusahaan nantinya. 


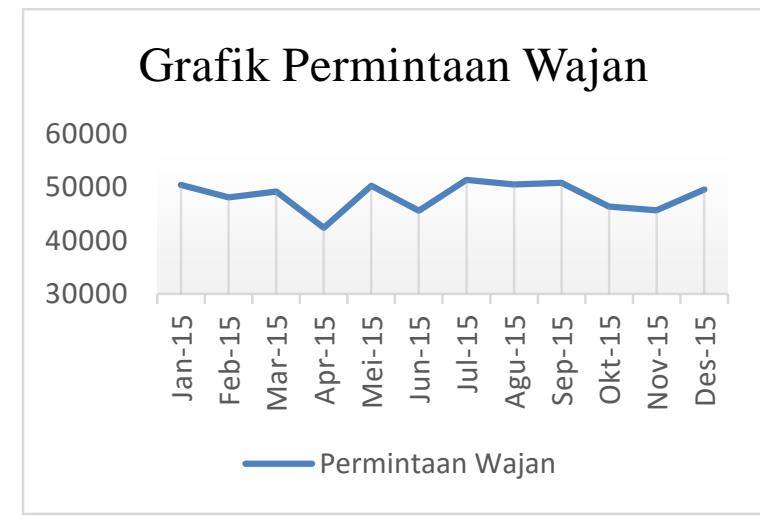

Gambar 4.4 Grafik Permintaan Wajan

Berdasarkan pada grafik pada Gambar 4.4, maka dapat ditentukan model peramalan yang akan digunakan. Model yang sesuai dengan grafik di atas adalah Moving Averages Model, Weighted Moving Averages Model, dan Single Exponential Smoothing Model.

Hasil peramalan yang dilakukan dengan menggunakan model-model terpilih menunjukkan bahwa hasil peramalan terbaik diberikan oleh model Single Exponential Smoothing. Hal tersebut dapat dilihat dari peta kontrol tracking signal yang dimiliki oleh model tersebut, di mana tracking signal-nya memiliki sebaran antara positive error dan negative error yang seimbang serta paling mendekati nol, hal tersebut mengindikasikan bahwa hasil peramalan yang dihasilkan model ini memiliki pola yang hampir sama dengan pola permintaan wajan di periode sebelumnya.

- Master Production Schedule (MPS)

Tabel 4.19 Master Production Schedule Wajan

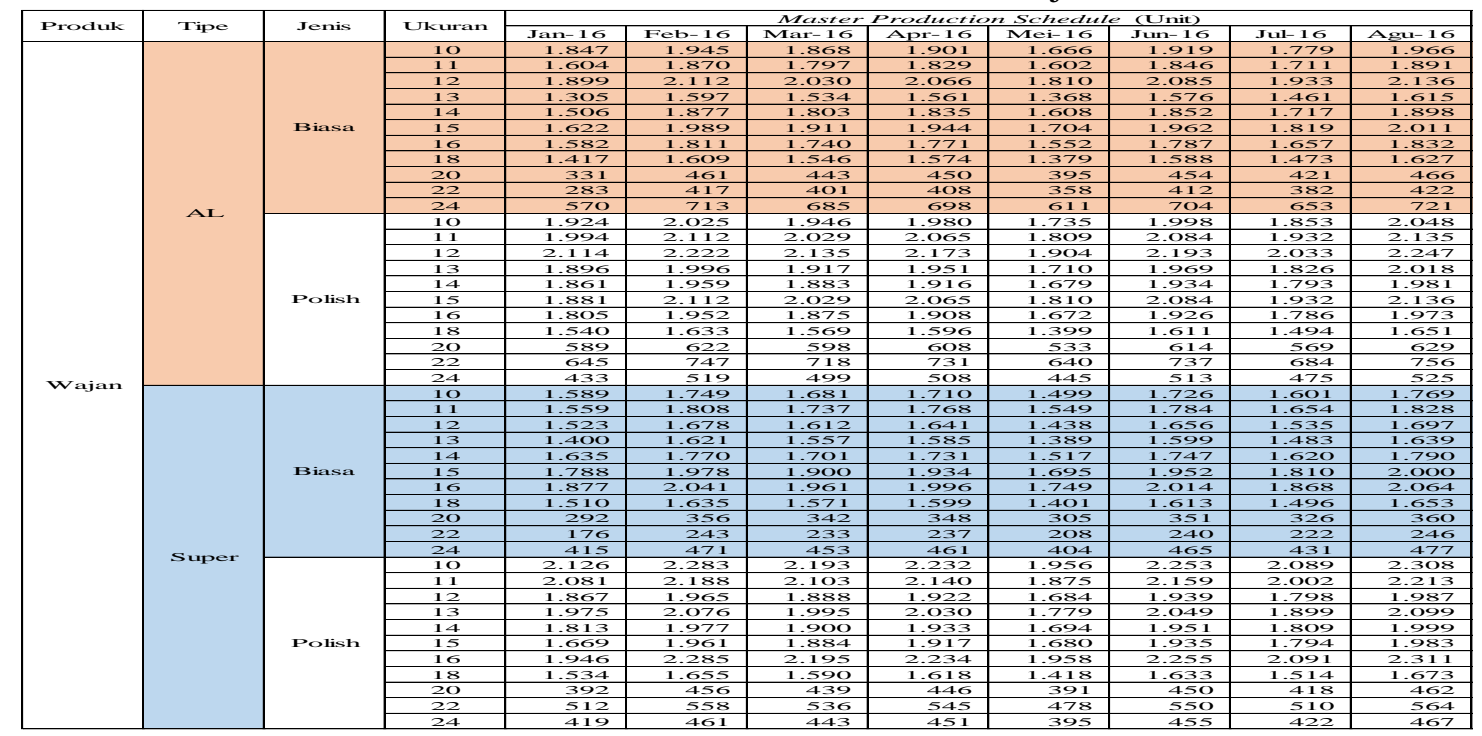

- $\quad$ Rough Cut Capacity Planning (RCCP)

Susunan MPS yang telah tersusun sebelumnya, akan diverifikasi terlebih dahulu oleh RCCP, untuk mengetahui apakah kapasitas yang tersedia di lantai produksi mampu melaksanakan jadwal yang telah disusun oleh MPS. Dalam penyusunan RCCP sendiri, kebutuhan kapasitas yang dikalkulasikan merupakan kebutuhan kapasitas untuk mengerjakan keseluruhan item. 
Berikut adalah load profile untuk masing-masing stasiun kerja :

\section{- $\quad$ Material Requirement Planning (MRP)}

Jadwal Induk Produksi yang telah diverifikasi oleh RCCP kemudian diteruskan menuju perencanaan kebutuhan material atau MRP. MRP disusun agar perusahaan dapat melakukan perencanaan kebutuhan material produksi dengan baik, sehingga material dapat diperoleh tepat pada waktunya dan datang dengan kuantitas yang tepat pula. Pada MRP, Gross Requirement (GR) diperoleh dari data permintaan pada MPS, di mana data yang pada MPS terakumula-si dalam permintaan bulanan, maka pada MRP permintaan tersebut dibagi men-jadi permintaan mingguan (1 bulan $=4$ minggu). Sehingga dalam perhitungan yang dicontohkan oleh Wajan AL Biasa "10" GR dari item tersebut :

GR = MPS per bulan Wajan AL Biasa "10" / 4 Minggu

$=1.847$ unit $/ 4$ minggu

$\mathrm{GR}=461$ unit / Minggu

Dari data GR yang telah diperoleh pada setiap periodenya, maka dapat dilakukan perhitungan kebutuhan material untuk item tersebut, di mana langkah perhitungan MRP dilaksanakan dengan urutan sebagai berikut :

1. Menentukan kebutuhan bersih (Net Requirements, NR) berdasarkan Gross Requirement yang telah diketahui pada tiap periodenya. Untuk menentukan NR pada periode pertama dapat digunakan Persamaan 2.21 sehingga dida-patkan NR seperti berikut ini :

$\mathrm{NR}=\mathrm{GR}+$ Allocation $+\mathrm{SS}-\mathrm{SR}-\mathrm{POH}_{t-1}$

$$
=462+0+25-0-30
$$

$$
=457 \text { Unit }
$$

2. Kebutuhan bersih yang telah diperhitungkan kemudian diturunkan menjadi planned order receipts, di mana jumlah pemesanan yang direncanakan sejumlah lot yang telah ditentukan oleh perusahaan.

3. Pesanan yang telah datang kemudian menjadi Projected on Hand $(\mathrm{PoH})$, di mana nilai PoH diketahui melaui Persamaan 2.20, sehingga diperoleh $\mathrm{PoH}$ pada awal periode sebagai berikut :

$\mathrm{PoH}=\mathrm{On}$ Hand periode awal $+\mathrm{SR}-\mathrm{GR}$

$=30+580-462$

$=148$ unit

- $\quad$ Capacity Requirement Planning (CRP)
MRP mengasumsikan bahwa apa yang dijadwalkan dapat diterapkan, tanpa memperhatikan keterbatasan kapasitas (Gaspersz, 2012). Perencanaan kebutuhan kapasitas (Capacity Requirement Planning, CRP) menguji asumsi tersebut dan mengidentifikas stasiun kerja yang melebihi kapasitas (overload) dan berada di bawah kapasitas (underload), sehingga dapat perusahaan dapat mengambil tindakan yang tepat. CRP membandingkan beban yang ditetapkan pada setiap stasiun kerja melalui planned order release yang sudah disusun oleh MRP dengan kapasitas yang tersedia pada setiap stasiun kerja dalam setiap periode waktu dari horizon perencanaan.

Berdasarkan pada kebutuhan kapasitas yang telah diperoleh sebelumnya, kemudian verifikasi dilakukan untuk memeriksa ketersediaan kapasitas un-tuk menjalankan produksi sesuai work order yang telah dikeluarkan oleh MRP. Ketersediaan kapasitas diperiksa menggunakan load profile untuk membandingkan kebutuhan dengan ketersediaan kapasitas. Berikut adalah load profile stasiun kerja yang mengalami kekurangan:

\section{Analisis Hasil}

- Analisis hasil peramalan

Peramalan permintaan menggunakan data historis permintaan selama bulan Januari hingga Desember 2015 guna memperoleh data permintaan hingga delapan bulan ke depan. Data yang diperoleh tersebut menunjukka pola bergelombang (cycle) sehingga dalam melakukan peramalan penulis memilih metode peramalan Moving Averages Model, Single Exponential Smoothing, dan Weighted Moving Averages.

Berdasarkan pada hasil peramalan menggunakan ketiga model tersebut, dapat dilihat pada Tabel $4.11,4.14$, dan 4.16 , bila ketiganya dibandingkan terlihat bahwa model Single Exponential Smoothing dengan menggunakan smoothness constant sebesar 0,9 memberikan hasil peramalan terbaik, karena memiliki nilai MAD terkecil dengan sebaran postive error dan negative error yang merata pada peta kontrol tracking signal. Pemilihan nilai smoothness constant sebesar 0,9 dilandasi oleh pola data historis permintaan yang fluktuatif sehingga diperlukan pemulusan yang tinggi agar model SES dapat melakukan penyesuaian yang baik terhadap pola data tersebut. Kemudian hasil peramalan yang diperoleh melalui model Single Exponential Smoothing ini menjadi dasar untuk menentukan jumlah permintaan di periode mendatang. 
- Analisis Kapasitas Produksi

Data permintaan bulan Januari-Agustus 2016 yang telah diperoleh melalui peramalan yang telah dilakukan sebelumnya menjadi acuan untuk disusunnya jadwal induk produksi. Untuk mengetahui apakah jadwal induk produksi yang telah tersusun dapat diproduksi maka dilakukan verifikasi terhadap kapasitas yang dibutuhkan untuk melakukan produksi sesuai jadwal yang telah tersusun menggunakan RCCP. Berdasarkan pada Tabel 4.21 dapat diketahui kekura-ngan kapasitas yang terjadi pada stasiun kerja Gerinda, Bubut, dan Polish. Kekurangan yang terjadi pada stasiun-stasiun kerja tersebut dapat diselesaikan dengan cara melakukan overtime, seperti yang terlihat pada Gambar 4.16 dan 4.17.

CRP menunjukkan bahwa telah terjadi kekurangan kapasitas pada stasiun kerja Cetak Wajan Super 15 dan 16, sert stasiun kerja Gerinda, Bubut, dan Polish. Untuk mengatasi kekurangan tersebut maka dilakukan penambahan kapasitas dengan cara melakukan lembur. Lembur yang dilakukan selama tiga jam mengakibatkan kekurangan yang tersisa hanya ada pada stasiun kerja Bubut pada periode 8 dan 31 dengan kekurangan sebesar 68,43 menit dan 943,44 menit. Kekurangan yang masih terjadi kemudian disbukontrakkan kepada pihak lain selaku mitra perusahaan, yaitu CV Prima AL, Mendungan.

\section{KESIMPULAN DAN SARAN}

\section{Kesimpulan}

Mengacu pada hasil pengolahan data yang dilakukan pada bab sebelumnya, dapat disimpulkan bahwa ketidakmampuan perusahaan untuk memenuhi permin-taan diakibatkan oleh kurangnya kapasitas produksi yang tersedia pada stasiun kerja Gerinda, Bubut, dan Polish. Berdasarkan fakta tersebut, maka perusahaan perlu melakukan suatu perencanaan strategis guna mengatasi kekurangan kapasitas pada dua stasiun tersebut.

Strategi yang dapat dilakukan oleh perusahaan agar dapat memenuhi permin-taan adalah dengan cara melakukan lembur pada stasiun kerja cetak wajan super ukuran 15 dan 16, Gerinda, Bubut, dan Polish. Lembur dilakukan selama tiga jam. Kemudian kekurangan yang masih terjadi pada stasiun kerja bubut di periode 8 dan 31 diselesaikan dengan cara melakukan subkontrak pekerjaan yang tersisa kepada mitra perusahaan, CV Prima AL, Mendungan.

\section{Saran}

Penelitian ini dapat dilanjutkan dengan meneliti permasalahan yang terjadi pada stasiun kerja yang menjadi bottleneck agar dapat diketahui secara pasti penyebab ketiga stasiun tersebut mengalami kekurangan kapasitas.

\section{DAFTAR PUSTAKA}

Bauer, A., Bowden, R., 1994, Shop Floor Control Systems : From Design to Implementation, Chapman \& Hall, London.

Bowersox, D \& Closs, D., 1996, Logistical Management : The Integrated Supply Chain Process, International ed., McGraw-Hill Book, Co., Singapore.

Fogarty, D., Blackstone, JR., J., 1991, Production \& Inventory Management, 2nd ed., South-Western Publishing Co., Ohio.

Gasperz, V., 2012, All-In-One : Production and Inventory Management for Supply Chain Professionals, edisi revisi., Vinchristo Publication, Bogor.

Narashiman, S., L., McLeavey, D., W., Billington, P., J., 1995, Production Planning and Inventory Control, Prentice-Hall, Inc., New Jersey.

Sheikh, K., 2002, Manufacturing Recource Planning (MRP II) With Introductio to ERP, SCM and CRM, International ed., McGraw-Hill, Co., Singapore.

Tersine, R., 1994, Priciples of Inventory and Materials Management, 4th ed., Prentice-Hall, Inc., New Jersey. 
